\title{
Strategic Environmental Assessment (SEA) Process for Sustainable Mining and Mineral Management Development
}

\author{
Vijayan Gurumurthy Iyer* \\ Department of Civil Engineering, Narasaraopeta Engineering College (Autonomous), Nararasaraopeta, India \\ Email: vijayaniyergurumurthy@rediffmail.com
}

How to cite this paper: Iyer, V.G. (2017) Strategic Environmental Assessment (SEA) Process for Sustainable Mining and Mineral Management Development. Open Access Library Journal, 4: e3422.

https://doi.org/10.4236/oalib.1103422

Received: February 3, 2017

Accepted: April 14, 2017

Published: April 17, 2017

Copyright (c) 2017 by author and Open Access Library Inc.

This work is licensed under the Creative Commons Attribution International License (CC BY 4.0).

http://creativecommons.org/licenses/by/4.0/

\section{c) (i) Open Access}

\begin{abstract}
Strategic environmental assessment (SEA) process can be broadly defined as a study of the impacts of a proposed project, plan, project, policy or legislative action on the environment and sustainability. SEA process has been aimed to incorporate environmental and sustainability factors into mining and mineral (MM) project planning and decision making (MMPPDM) process. Sustainable MM development is a kind of development that meets the needs of the present without compromising the ability and efficacy of future generations to meet their own MM needs. Environmental Impact Assessment (EIA) process can be defined as the systematic study of the potential impacts (effects) of proposed MM projects, plans, programs, policies or legislative actions relative to the physical-chemical, biological, cultural, and socio-economic components of the total environmental product life cycle. The primary purpose of the EIA process is to encourage the consideration of the environment in MMPPDM process and to arrive at actions that are environmentally compatible. MMPPDM process should include the integrated consideration of technical or engineering, economic, environmental, safety, and health, social and sustainability factors to achieve business excellence. The objective of the study is to conceptualize SEA process for the MM sector based on fifteen number of sustainable detailed project reports (DPRs) submitted by the extension learners of Diploma in Entrepreneurship and Business Management (DEBM) course conducted by the Entrepreneurship Development Institute of India (The EDI of India) during the research year (RY) 1999 to 2017 under the author's counsellorship. The design of the study is cross-sectional. EIA and Environmental Health Impact Assessment process has been conducted for Odissa chromite mining plants to consider the safety and health impacts to mitigate environmental health impacts on miners and nearby residents. Social Impact Assessment (SIA) process can be defined as the systematic identification and evalua-
\end{abstract}


tion of the potential social impacts (effects) of proposed projects, plans, programs, or legislative actions such that social consideration is encouraged in MMPPDM process and to arrive at actions that are socially compatible about a chromite mining project. SEA process concerns to environmental and sustainable effects in MMPPDM process and arrives at proposed projects, plans, programs, and legislative actions that are compatible with respect to environmental and sustainable issues. Mining and mineral industrial product environmental life cycle analysis (LCA) is used for identifying and measuring the impact of MM industrial products on the environment and sustainability. These environmental impact assessments consider activities related to extraction of raw materials such as metal, coal and minerals, ancillary materials, equipment; production, use, disposal and ancillary equipment by means of mass and energy balance methods. A case study on unsafe chromium and environmental health impact assessment (EHIA) process for Odissa chromite mine plants has been discussed. International EIA process requires a multi-disciplinary approach that should be conducted at very early stage of MM project for the SEA process. As far as the MM safety is concerned personal protective equipment and materials (PPEMs) that include garments, clothing, gloves, safety shoes, hard hats, safety glasses, shields, respirators, full aprons, safety belts, and other safety items which must be used by an individual. Such equipment is important for personal protection and for safety. It is the MM manager's and supervisor's responsibility to ensure that they are used. Blast impact assessment (BIA) is the systematic identification and evaluation of potential blast effects of proposed blast projects, plans, programs, policies or legislative actions relative to the physical, chemical, biological, cultural, socio-economic, archeological and other man-made environmental components of the total environment. The enactment of miner's compensation law and occupational disease law shall increase materially the cost of insurance to the MM industry. The increased cost and the certainty with which it is applied will put a premium on accident-prevention work. This cost can be materially reduced by the installation of MM safety devices. MM management research experience has shown that approximately $80 \%$ of all the mining accidents are preventable. SEA system is a potentially useful element of good environmental management and sustainable development; however, as currently practiced in mines, it is far from perfection. Emphasis should be given in MM industries on maintaining economic viability of the operation, while in turn taking care to preserve the ecological and social sustainability of the country. The MM sustainability assessment or SEA process protocol is a sector specific method for checking the right quality and uniformity of environmental and social assessments and management plans. This treaty and official Government procedures of SEA are helpful for making much earlier decisions in the decision-making process than EIA. Therefore, it is key tool for sustainable MM development. SEA aims to incorporate environmental and sustainable considerations into strategic decision making processes, to formulate and appraise projects, policies, plans, and programs and legislative actions. 


\section{Subject Areas}

Mineral Engineering

\section{Keywords}

Blast Impact Assessment, Education, Environment, Management, Mining, Mineral, Process Approach, Strategic, Sustainability

\section{Introduction}

SEA can be defined as a planning and decision making tool to identify, understand, assess and mitigate, where possible, the environmental and sustainable effect of a project. Prior to the national environmental policy act (NEPA) process in 1970 in the USA, technical and economic factors dominate the world's MM projects. Mining and mineral industrial product environmental life cycle analysis (LCA) is used for identifying and measuring the impact of MM industrial products on the environment. Environmental impact assessment considers activities related to extraction of raw materials, blasting impacts during exploration and exploitation of minerals, ecological impacts, ancillary materials, equipment; production, use, disposal and ancillary equipment [1]. The SEA is a concise document protocol prepared that serves to:

1) Briefly provide sufficient evidence and analysis for determining whether to prepare a SEA statement or a Finding of No Significant Sustainability Impact (FONSSI);

2) Demonstrate compliance with the act when no SEA statement is required;

3) Facilitate the preparation of SEA statement when a FONSSI cannot be demonstrated.

The legislation of EIA process was established in 1970 by the enactment of the National Environmental Policy Act (NEPA) in the USA [2]. This was the first time that EIA process became an official tool in projects, plans, programs, legislative actions, policies to protect the environment [3]. Three of the significant terms for environmental analysis while complying with the requirements of NEPA process are, "environmental inventory", "environmental impact assessment process", and "environment impact statement". EIAs of design and construction of mining and mineral technological structures were undertaken to protect environment during the year 1950 in Japan, Europe and North America [4]. The purpose of the EIA process is to encourage the consideration of the environment in organizational planning and decision making process that should include blast impact assessment [5]. Historically, the choice of proposed projects, policies, plans, programs, permits, procedures or legislations was primarily based on only one criterion called economic viability. Today, it is necessary to consider three criteria of economic, environmental and social viabilities. Environment coupled with quality management (EQM) is an intricate mining and mineral managerial approach that is the targeted research area to achieve 
sustainable socio-economic improvement based on the triple bottom-line approach (economical, environmental and social) feasibility studies [6]. In this paper systematic identification and evaluation of the advanced technologies in context to the Indian exploration and exploitation of mining and mineral processing has been studied with special reference to the environmental impact assessment process, solid and hazardous waste management, environmental product lifecycle assessment, environmental health impact assessment, international environmental impact assessment process, blasting impact assessment, international social impact assessment process, strategic environmental assessment process, sustainable mining and mineral science, technology and managerial development, sustainable advanced technology in exploration and exploitation of minerals towards sustainable development [7].

\section{Materials and Methods}

SEA process is a predictable process that is devised in to two phases [8]. The first phase is called initial environmental and sustainability evaluation (IESE) and the second phase is environmental and sustainability impact studies (ESIS). IESE has been carried out for Japanese Matsushita carbon company's proposed project, plan, program, policy, permit, procedure, and legislative action in India to determine whether potentially adverse effects on environment and sustain efficacy with respect to physical, chemical, biological, economical, socio-economic environment and on human health and well-being are significant or whether mitigation measures can be adopted to reduce or eliminate adverse environmental and sustainability impacts. Detailed SEA procedure can be called as ESIS that was applied to identify and evaluate the environmental and sustainability consequences both beneficial and adverse impacts to ensure that the environmental and sustainability impacts were taken in to consideration in organization's planning and decision making process. SEA process is designed to identify and predict the potential impacts of the physical, biological, ecological, socio-economic, cultural environment and on human health and well-being are adequately protected [8]. Given below some of the methods and techniques applied for the sustainable project formulation and appraisal of fifteen DEBM extension learners of The EDI of India attached with the professional counsellor and co-ordinator.

1) Expert judgment and stakeholders' sentiments

2) Check list and matrices

3) Multi criteria analysis

4) Case comparisons

5) Simulation models

6) Software and information system

7) Questionnaires

8) Group discussions

9) Delphi approach

10) Flow charts and decision trees

11) Contingency analysis

12) Overlays 


\section{3) Fuzzy logics}

Environment and sustainability compliance requirements have been identified and evaluated systematically in these projects. Fifteen DPRs of DEBM Learners were formulated and appraised (http://www.ediindia.org/doc/list of institutions for website latest.pdf.serialnumber68). (http://debm.ediindia.ac.in; Agency code: 80410, Password: 80410).

A case study on unsafe chromium and environmental health impact assessment process for Odissa chromite mine plants is discussed for the implementation of SEA process as it is considered as hazardous environment [9]. Odissa accounts for 95 percent of the chromium ore reserves of India. It increases the economic status, but adversely reduces the ecological cover. Chromite mines generate considerable quantity of pollutants containing toxic hexavalent chromium, a known carcinogen, which contaminates 10 to $4000 \mathrm{mg} / \mathrm{kg}$ (ppm) of total chromium in air, water and soil environment. Surface water and ground water in Sukinda region contain hexavalent chromium Cr (VI), well above the permissible limits of $0.05 \mathrm{mg} / \mathrm{l}(\mathrm{ppm})$. There are clusters of chromite mines release considerable quantity of effluents and slurries, as well as the over burden stockpiles as hazardous wastes. These are discharged into various tributaries of the Brahmani River. Suspended and respirable particulate matters are found well above the prescribed limit of $100 \mu \mathrm{g} / \mathrm{m}^{3}$. Chromium based diseases among the miners have been found which could be a result of the intake of excessive $\mathrm{Cr}$ (VI). Chromite miners and residents, who were constantly exposed to contaminated dust and water, report gastrointestinal bleeding, tuberculosis and asthma besides incidence of infertility, birth defects and still births. They suffer from chromium based diseases such as chromium poisoning, ulcer, allergic dermatitis, lung cancer, lever necrosis, brain damage, premature death, lever and kidney problems [10]. It is important that these mines must initiate regulatory measures to control this unsafe chromium pollution. It is required to get treated this mine water using chromium effluent treatment plants (CETP) as well as to get evolved preventive and control strategies at the planning stages itself as prevention is better than cure, very little or nothing can be done if the toxic chromium reaches the air, water and soil environment. It has been observed that the management of chromite mines has not implemented the miner's compensation law and occupational diseases law. As per the present research work conducted, it has been proved that approximately 80 percent of mining disasters are preventable if these laws get enforced efficiently. It is necessary that the miners must follow adequate safety compliances. Blast impact assessment should be conducted for blast projects based on given steps [10].

\subsection{Step-Wise Structure of SEA Process}

SEA Process has been itemized by the following nine steps.

1) Preliminary activities and decision of Terms of References (TOR)

2) Scoping 
3) Study of baseline data

4) Strategic environmental assessment and evaluation

5) Evaluation of alternative measures

6) Assessment of alternative measures

7) Preparation of final documents

8) Decision-making

9) Monitoring, measurement and control opportunities for resource transformation and project implementation and its strategic environmental assessment process.

\subsection{Conceptual Framework for Screening and Scoping of SEA Process}

Screening and scoping processes are the items which are employed in the SEA processes (Figure 1).

Three most significant items are, "Strategic environmental assessment inventory, environmental impact assessment, strategic environmental impact assessment statement. Constructional planning and decision making process should include the integrated consideration of technical, economic, environmental, social, safety, health and sustainability factors (Figure 2).

\subsection{Strategic Environmental Assessment Management Plan (SEMP)}

A strategic environmental assessment management plan is a detailed plan and schedule for measures to minimize and mitigate any potential environmental and sustain efficacy impacts. SEMP should consists of set of measurements, monitoring, control (mitigative) and institutional measures to be taken during the implementation and operation of the proposed projects to eliminate adverse environmental and sustainability impacts, offset them or reduce them to acceptable levels. Strategic environmental assessment process aims to incorporate environmental and sustainability considerations in to strategic planning and decision making processes of the project formulation and appraisal. International

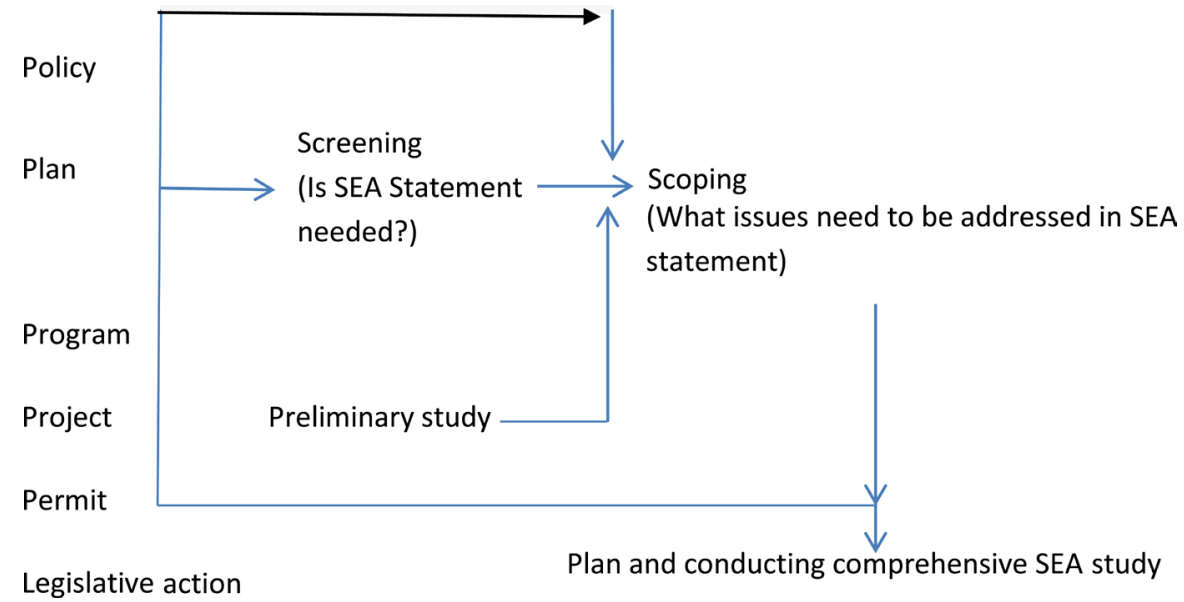

Figure 1. Conceptual framework for screening and scoping process of the SEA process. 


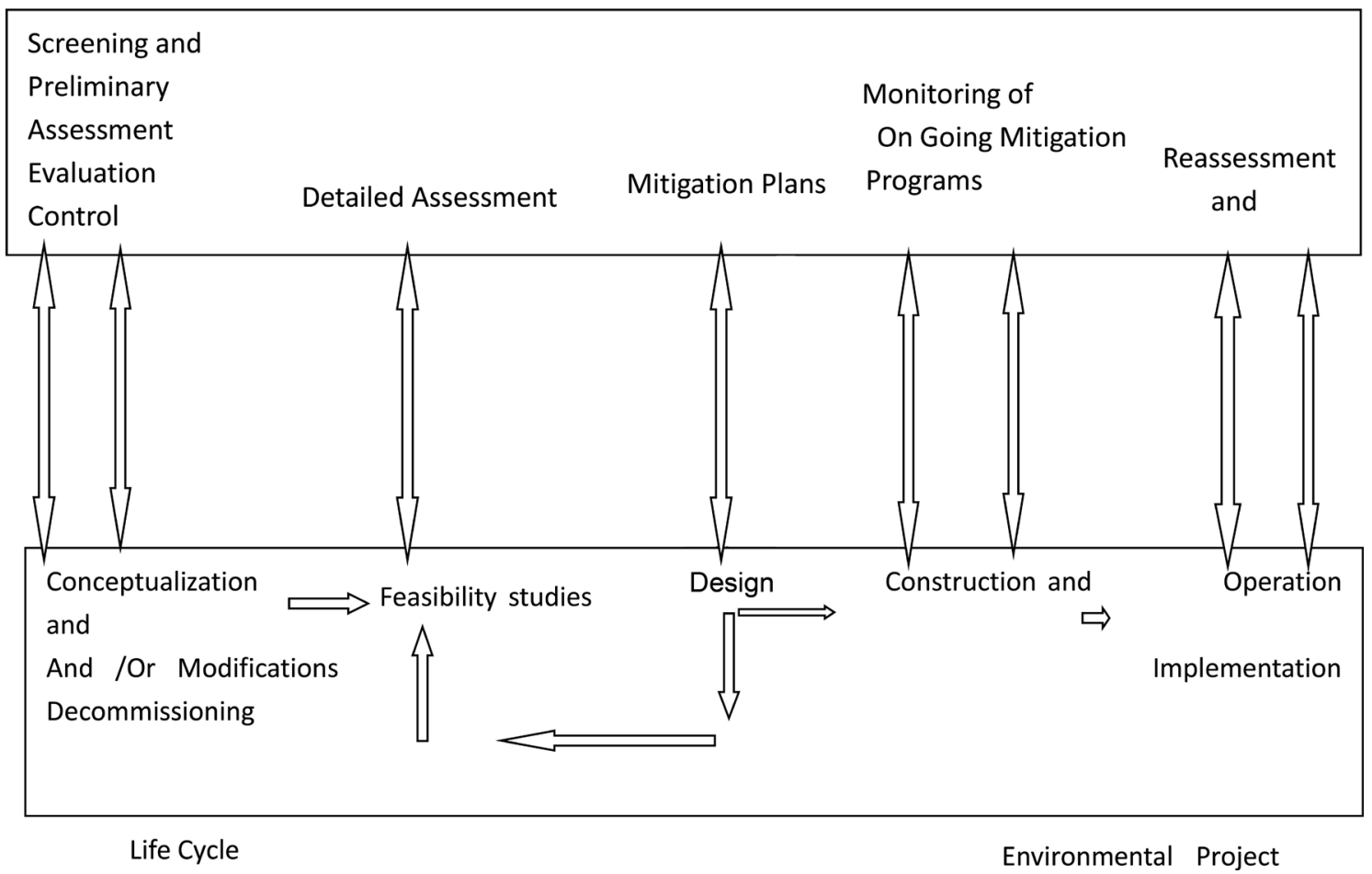

Figure 2. Strategic environmental assessment (SEA) process undertaken at various phases of the environmental project life cycle assessment (LCA).

EIAs are important considerations in project planning and decision making process [11]. It has been imperative to consider international EIAs in mining and mineral project to mitigate $\mathrm{CO}_{2}$-induced climate warming problem and stratospheric ozone depletion problem. International EIA process is a potentially good environmental management [11].

\section{Results and Discussions}

During the last two centuries, due to the fast urbanization and industrialization along with advancement of mining and mineral Science, Engineering and Technology, there have been considerable developments in MM sector with the resultant wastage of copious amount of resources, environmental pollution and disproportional environmental stress affecting quality of life. Subsequently, it was realized that there were many adverse impacts on environment and society. These unsustainable mineral and mining developments have sustained the environmental and sustainability growth [12]. Sustainability of design and development, quality of life, safety on earth and continuous process improvement of our environment is of utmost important. Sustainable mining and mineral development means a kind of development that meets the needs of the present without compromising the ability and efficiency of future generations to meet their mining and mineral needs. Hence, hectic mining and mineral developmental activities during the last two centuries have caused considerable environmental and social impacts. These impacts have been measured, monitored and mitigated by international environmental impact assessment process (Figure 3). 
International EIAs are important in international project planning and decision making process that mitigates potential environmental impacts in more than one country [13]. The use of sustainable mining and mineral technologies and management in environmental and sustainability matters in two areas that is sustainable development with global problems and prevention technologies that are designed to reduce the environment effects of products and processes (Figure 4).

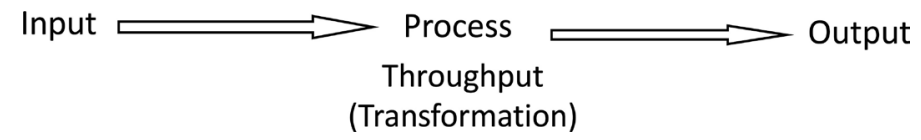

Figure 3. Schematic Representation of Showing the Process Approach of Sustainable Mining and Mineral Management Development.

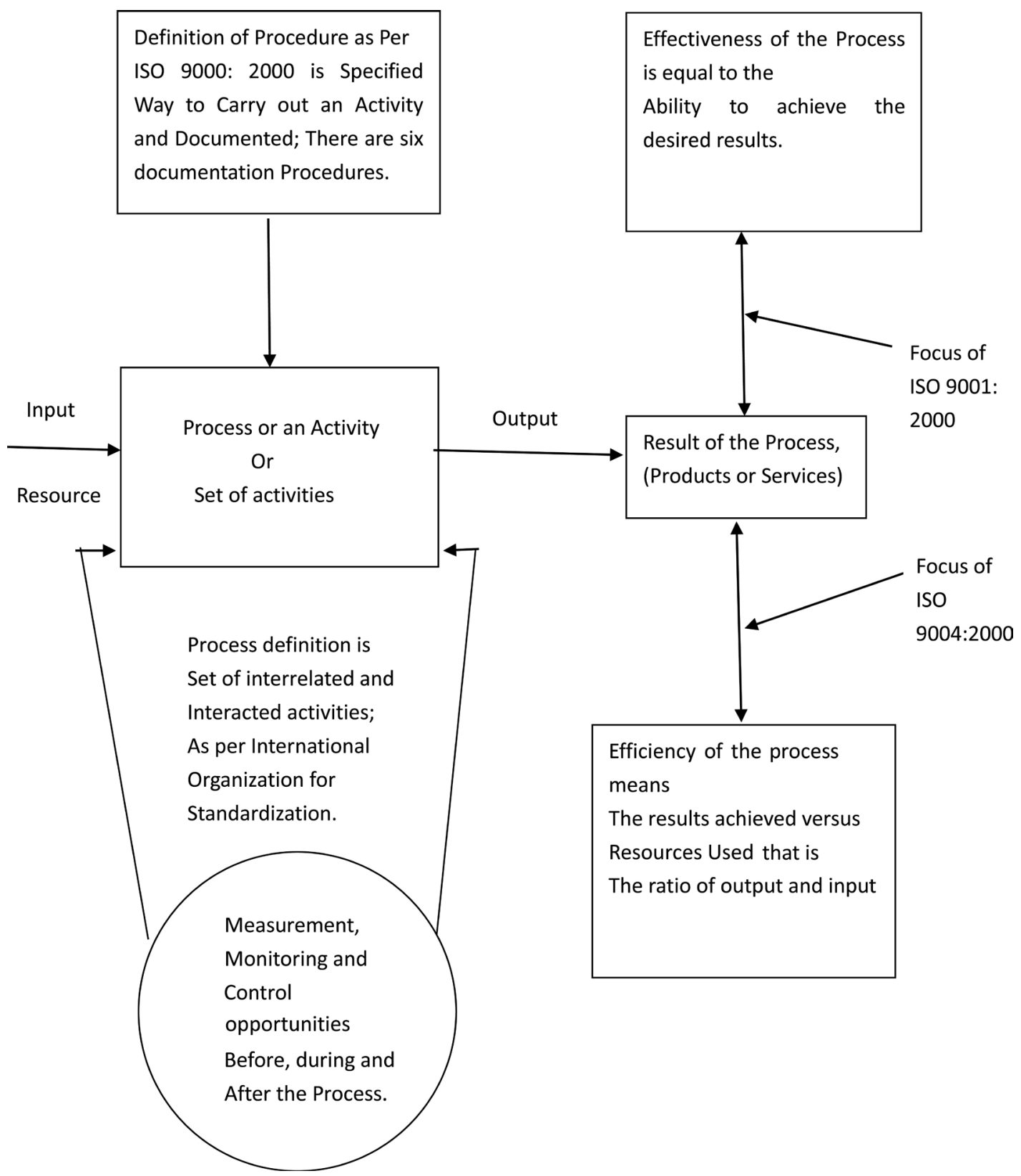

Figure 4. Schematic representation diagram of mining and mineral exploration and exploitation process. 
The integration of environmental protection and economic development is the most important strategic environmental assessment tool in achieving sustainable development (Figure 5).

Project planning and decision-making should include the integrative consideration of engineering or technical, economic, environmental, ethical and social factors. A midget electrode project was taken as a case study for the strategic environmental assessment process (Figure 5 and Figure 6). International EIA process has been designed for the sustainable midget electrode project design and construction to identify and predict the potential effects of the physical, biological, ecological, socio-economic, cultural environment and on human health and well-being are adequately protected. Environmental Impact Statements (EIS/BIS) have been prepared for the project while considering environmental and socio-economic factors with respect to development and other proposed actions. Therefore, the EIA /BIA system is a potentially useful component of good environmental management [12]. A case study on unsafe chromium and environmental health impact assessment (EHIA) process of Odissa chromite mines is discussed as environmental and sustainability issues.

The water from Odissa chromite mines are invariably contaminated with hexavalent chromium. Mine water is released into the adjoining water sources (drinking and domestic) without treatment. The slag is usually dumped underground. This contains chromium compounds in different valence state. Hexava-

All Environmental and Sustainability Impacts Occur during the Exploration and Exploitation of Minerals

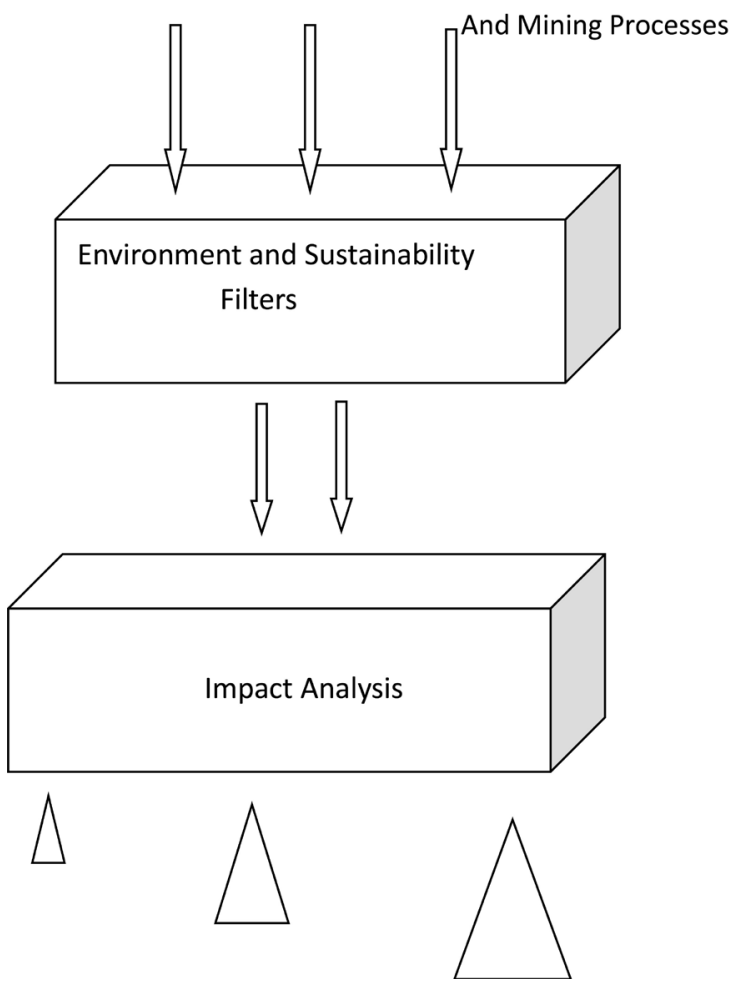

Figure 5. Procedures to find out the significance of environmental and sustainability impacts. 


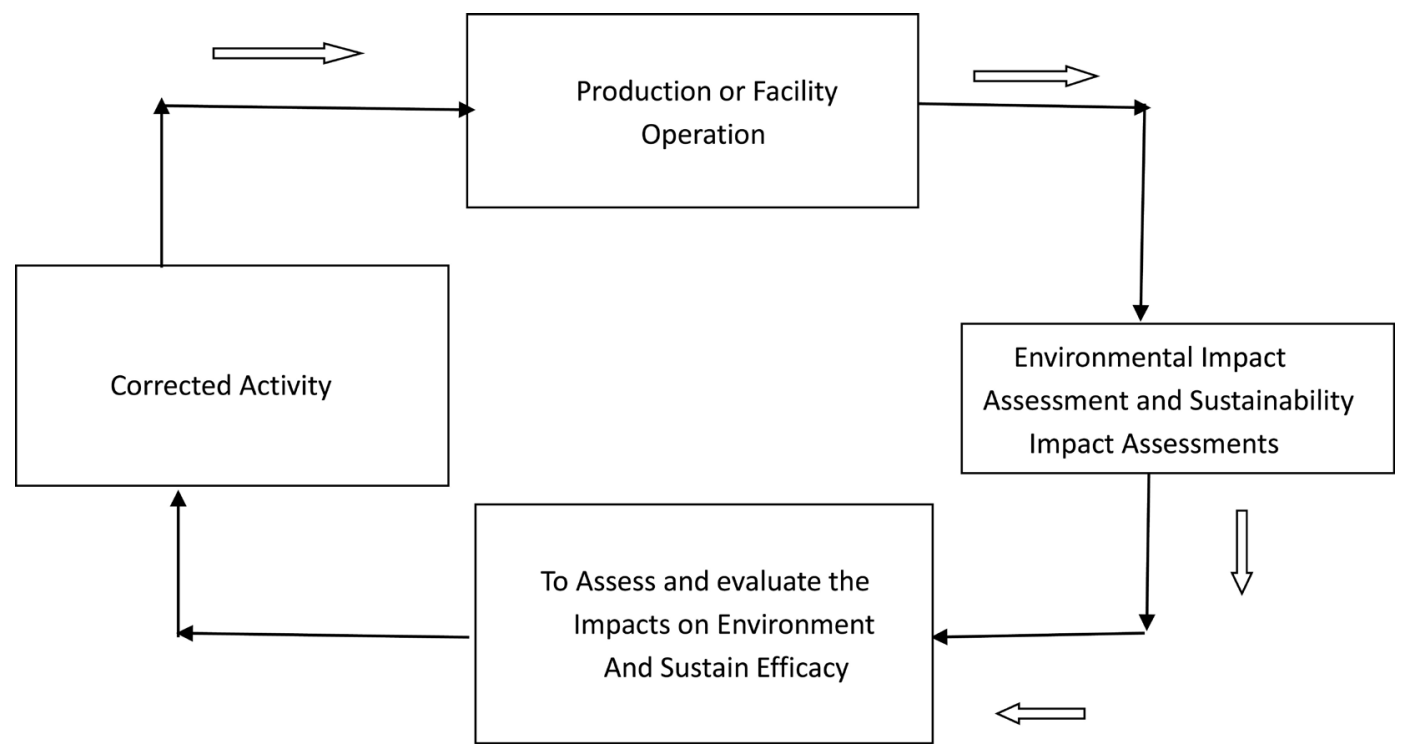

Figure 6. Environmental and sustainability management for a midget electrode project entitled "after-the -fact" evaluation.

lent chromium is formed due to still unknown chemical reactions and this percolates to the subsoil and terrestrial water sources during the rainy season. Sometimes the slag is manually broken and washed to retrieve the product and in this process, some contaminated water and shine are generated. Hexavalent chromium, $\mathrm{Cr}(\mathrm{VI})$ ) does not bind to soil and is not affected unless there is some organic matter. Chromium levels in mines water was tested by using Atomic Absorption Spectrophotometer (AAS). It was found that chromium content in the ground water is higher than $31 \mathrm{mg} / \mathrm{l}$ as against the safe limits of $0.1 \mathrm{mg} / \mathrm{l}$. [14]. Effluents are causing irreversible damage to the subsoil and surface water sources in adjoining areas and waste dumping sites. Hexavalent chromium content in certain parts of Odissa chromite plants has been found to be $550-1500$ ppm (mg/l) in well water, $25-100 \mathrm{ppm}$ in irrigation reservoirs and $4000 \mathrm{ppm}$ $(\mathrm{mg} / \mathrm{l})$ in the soil making it unfit for domestic usages. Trivalent chromium $\mathrm{Cr}$ (VI) is considered an essential micronutrient for physiological activity. However, most of the interference on the effects on (a) Glucose metabolism, (b) lipid metabolism (c) life spans, (d) life growth \& (e) life reproduction, were from studies on laboratory animals. Most of the daily human chromium uptake is ranging 50 - 200 micrograms which is through food in trivalent form, out of which a negligible portion that is $0.5 \%-3 \%$ is absorbed in the gastrointestinal tract and the rest exerted in Urine. The small ions of $\mathrm{Cr}$ (VI) get lodged in the perforations in the human cell water. After entering the cells, Cr (VI) ions get reduced in $\mathrm{Cr}$ (III) ions which are slightly bigger and then get stuck in the walls. The lethal usual dose for soluble chromite is $50 \mathrm{mg} / \mathrm{kg}$ of body weight. The clinical symptoms of acute toxicity are vomiting, diarrhea, blood loss into the gastrointestinal tract causing cardiovascular diseases. Exposure to small quantities of chromium cannot be avoided due to indifference of the miners and local residents in chromium based industries. Toxic effects are produced by prolonged contact with 
airborne or solid or liquid chromium compounds even in small quantities. Prolonged exposure to $\mathrm{Cr}$ (VI) causes ulcers, skin irritation and allergic dermatitis. Exposure to chromite dust or Cr (VI) may cause perforation of nasal septum, corrosion of bronchopulmonary tract and lung cancers. In the kidneys, it causes tubular necrosis and may also damage the liver. Chromium exposure may even lead to brain damages.

It is required to enact Miner's Compensation Laws and Occupational Diseases Law. As per the research studies conducted, it has been proved that approximately 80 percent of mines related disasters are preventable. The principle involved Miner's compensation laws and occupational diseases law is that the miner injured or disabled in mines should be enabled, through proper medical treatment, to return to wage-earning capacity as promptly as possible and, while incapacitated, should receive compensation in lieu of wages, regardless of fault. The expenses of medical treatment and compensation should properly be borne by mine management and become a part of the cost of its products. The laws generally provide that miners injured in industry shall be furnished the necessary medical treatment, and, in addition, compensation based on a percentage of their average weekly wages, payable periodically. Dependents of employees killed in mines are likewise compensated. They must be supplemented their miner's compensation laws by providing comparable benefits in cases of incapacity or death due to occupational disease. They make these provisions applicable only in case of specified occupational diseases; others make them of general application to cases of any disease directly attributable to the employment. Management of the industries may provide for compensation benefits in occupational disease cases either by enlarging the scope of the miner's compensation law, by separate legislative enactment, or by judicial constructions. The enactment of miner's compensation laws must be followed in many jurisdictions by more stringent provisions relating to factory inspections for the prevention of accidents in industry and of occupational disease that should include blast impact assessment studies. The enactment of miner's compensation and occupational-disease laws will increase materially the cost of insurance to industry. The increased cost and the certainty with which it is applied have put a premium on accident- prevention work. This cost can be materially reduced by the installation of safety devices.

As per the MM product life cycle assessment report and requirement for BIAin MM projects, chromium contamination and pollution takes place beyond safe limits which seriously affect the life on the earth [14]. Toxic emissions from industries, thermal power plants, smelting pollution, auto exhaust pollution in large metropolitan areas, photo chemical smog have been poisoning the atmosphere beyond the permissible levels which causes serious health hazards. Air pollution causes adverse environmental health and social impacts. Mindless disposal of untreated industrial wastes in Odissa chromite mines and other radio-active wastes in nuclear power plants, mining construction debris, hazardous wastes, blast effects, municipal solid waste, hazardous waste, agricultural 
wastes, domestic wastes have contaminated and polluted the water, soil and land beyond the tolerable limits, which adversely affects land fertility, water quality, vegetation, aquatic and marine life. This is proving more and more hazardous as this development continuously damaging the environment viz., melting of glaciers, climate change, carbon tetra chloride emission, greenhouse gas emission, ozone layer depletion. For example, due to continuous increase in $\mathrm{CO}_{2}$ concentration in the atmosphere due to industrial emission of about $382 \mathrm{ppm}$ which lead to climate change. This decrease in glaciers contributes to about $29.5 \%$ of mean sea level rise since 1991. Water supplies stored in the glaciers were projected to decline. Besides contaminating and polluting air, water, soil and land, intensive technological activities lead to depletion of natural resources [14].

This must have been sustained to bring our energy and intellectual capacity in tandem whereby that can meet the challenge efficiently without major disruption as well as without compromising on the livelihood of future generation of their needs. Development would have occurred without damages to the environment and major disruption, and the process of urbanization and industrialization would have occurred in sustainable manner by utilizing the resources efficiently. Now, these environmental problems are the present environmental challenges and opportunities for improvement. To overcome these environmental problems that shall require new and more efficient solutions, technologies, processes and products alongside behavioral change.

Low carbon and energy efficient technology of mining and mineral industries can make contributions to mitigating impacts of economic growth on global warming (Figure 7) [15].

The resultant output of green products and services which are environmental advantages with good performance and cheaper prices. The dual goals of green design are the waste prevention and better material management as depicted in Figure 7. Design and construction of green buildings that has considerably reduced the environmental impacts associated with manufacturing, use and disposal [15].

Prior to the enactment of National Environmental Policy Act on Environment in 1970 in the USA, only technical or engineering and economic factors dominant in planning and decision making process in most of the world projects, plans, programs, permits, policies and legislative actions. As per the research results that project planning and decision-making process must include the integrated consideration of engineering or technical, economic, environmental, safety, ethical, social and sustainability factors. This important consideration can be referred to as "Concept of the Four Es and $1 \mathrm{~S}$ " in organizational planning and decision making process. There are ecological and biogeochemical principles and tools such as energy flows and material cycling, element ratios, mass and energy balance, element cycling, product environmental life cycle assessment (LCA) (Figure 8) are available in order to solve major environmental problems that we face in our world today such as global warming, acid rain, environmental pollution and increasing greenhouse gases [15]. 


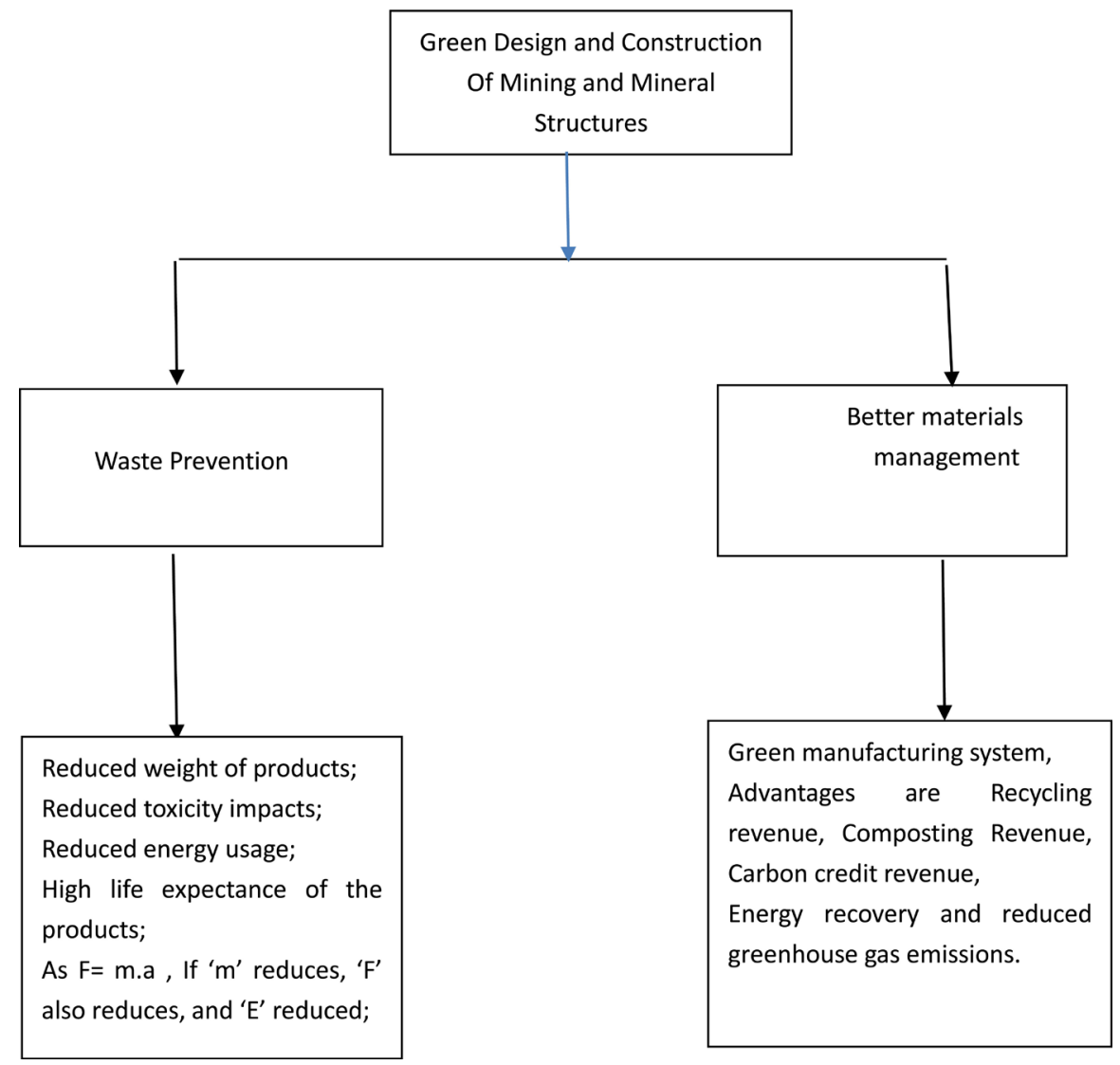

Figure 7. Dual goals of green design and manufacturing process of mining and mineral engineering products and services.

\subsection{Product Environmental Life Cycle Analysis (LCA)}

Mining and Mineral Industrial product environmental lifecycle analysis (LCA) is used for identifying and measuring the impact of industrial products on the environment and sustain efficacy by means of mass and energy balance methods (Figure 8). LCA consider the activities related to extraction of raw materials include BIA studies, ancillary materials, equipment production, use, disposal and ancillary equipment.

\subsection{International EIA Process}

International EIA process is a potentially good environmental management system (EMS). International organization for Standardization (ISO)'s 14,000 and 9000 standards focus on Environmental Management System (EMS) and Quality Management System (QMS) of all sorts of organizations apart from more than 19,500 published standards. Environmental Management System (EMS) and Quality Management System (QMS) have been separately featured in ISO. Environmental Management System (EMS) standards apply to the management system concepts of an organization's environmental issues and opportunities [16]. It defines the features of an EMS that need to be in place to ensure that the organization identifies and focuses on improving areas where they have significant environmental impacts. This system can be integrated with ISO 9000 Qual- 


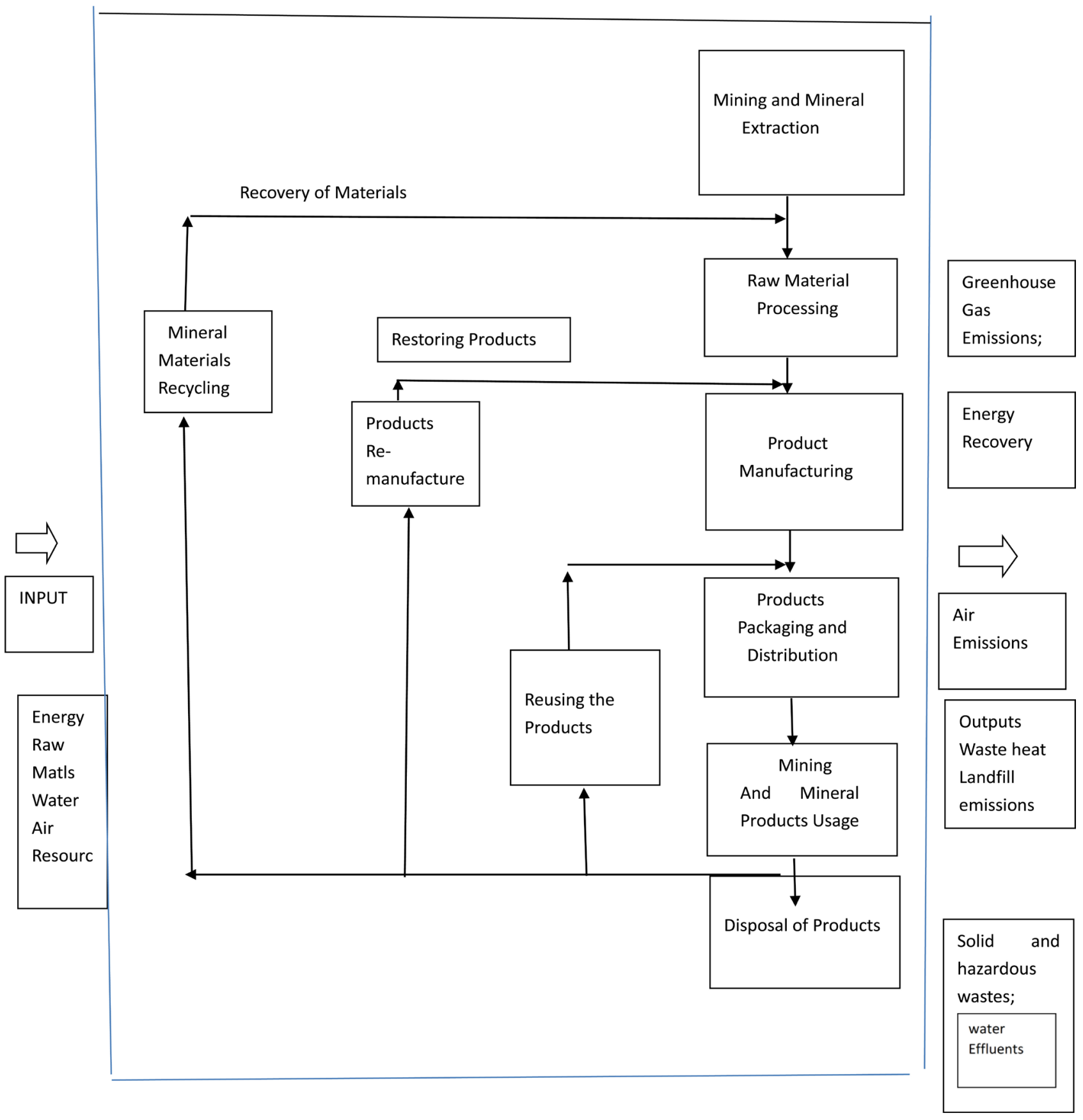

Figure 8. Environmental product life-cycle assessment of mining and mineral processing.

ity Management System (QMS) standards to achieve excellence in quality as well as environmental obligations. The overall aim of the EMS is to provide protection to the environment and to prevent pollution to manufacture eco-friendly products and services. EMS focuses on key drives of performance excellence in products and processes as well as organizations that are focused on delivering values to the customers, internal operational processes, and to staff's learning. Hence, this system approach to the environmental management shall achieve excellence in the overall performance of the organization. In the present study about two third of construction waste was recoverable due to the conduction in- 
tensive on-site training programs on recycling and composting processes as against the conventional mining and mineral extraction and exploitation practices which could able to recover the waste of only $10 \%$ to $15 \%$.

Mining and Mineral wastes are produced by mining and mineral sector. The study has been attempted to identify and evaluate special waste minimization hierarchy of waste management for properly managing MM waste including minimizing generation and treatment that have been generated, and disposing of waste residuals. A case study has been included on generation of MM wastes and potential waste management strategies for a group or generic construction processes. All MM processes generate wastes in the form of liquids, solids or gases. Some wastes are considered as hazardous. The waste minimization hierarchy of waste management is duly ranked from most desirable to least desirable (Figure 9).

1) Eliminating waste generation-Most desirable,

2) Reducing waste generation-Most desirable,

3) Reuse, recover or recycle waste materials-Most desirable,

4) Treating waste to diminish quantity and to detoxify the hazardous and nonhazardous solid wastes-Least desirable,

5) Disposing of waste residuals_Least desirable.

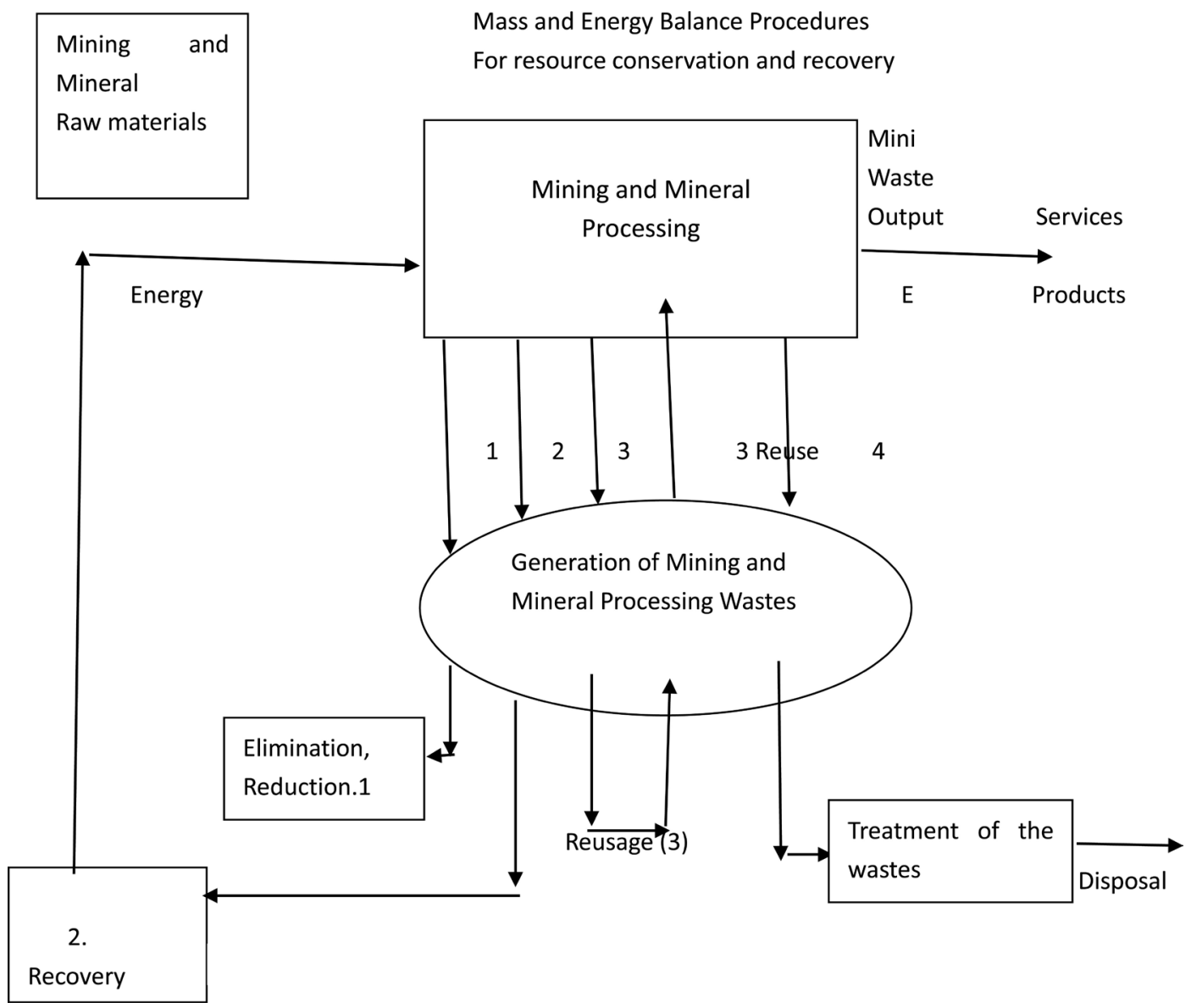

Figure 9. Schematic diagram of mining and mineral exploration and exploitation representing sustainable mining and mineral management development. 
Waste minimization includes only elimination, recovery, reduce, reuse and recycle hierarchies. Waste minimization does not include treatment of wastes as well disposal that is point number 4 and point number 5 because, these are traditional waste control strategies involves treatment and disposal which are called end-of-the pipe solutions and are costly affairs as well as involve control of high discharge standards. Modern waste control strategies involve point number 1, point number 2 and point number 3 which are not requiring end-of-the pipe solution for the waste management problems. Solid and hazardous waste generation is the sum of material recovery and discards. Report on waste audit conducted for a mining and mineral industry is presented for recovering two-third of solid wastes (MSW) by recycling and composting processes (Figure 10 and Figure 11).

To achieve the sustainable economic improvement, natural resources to be utilized at optimum level to maximize efficiency as per the result analysis of optimum competitive and social markets. The efficiency of a kind of sustainable economic system is referred in " $A . K$ " sustainable economic model that is the product of engineering or technical factor level (A) and the capital (K). The sustainable economic improvement is explained by three factors which are given below.

The natural increase in the accumulation of labor potential, Capital accumula-

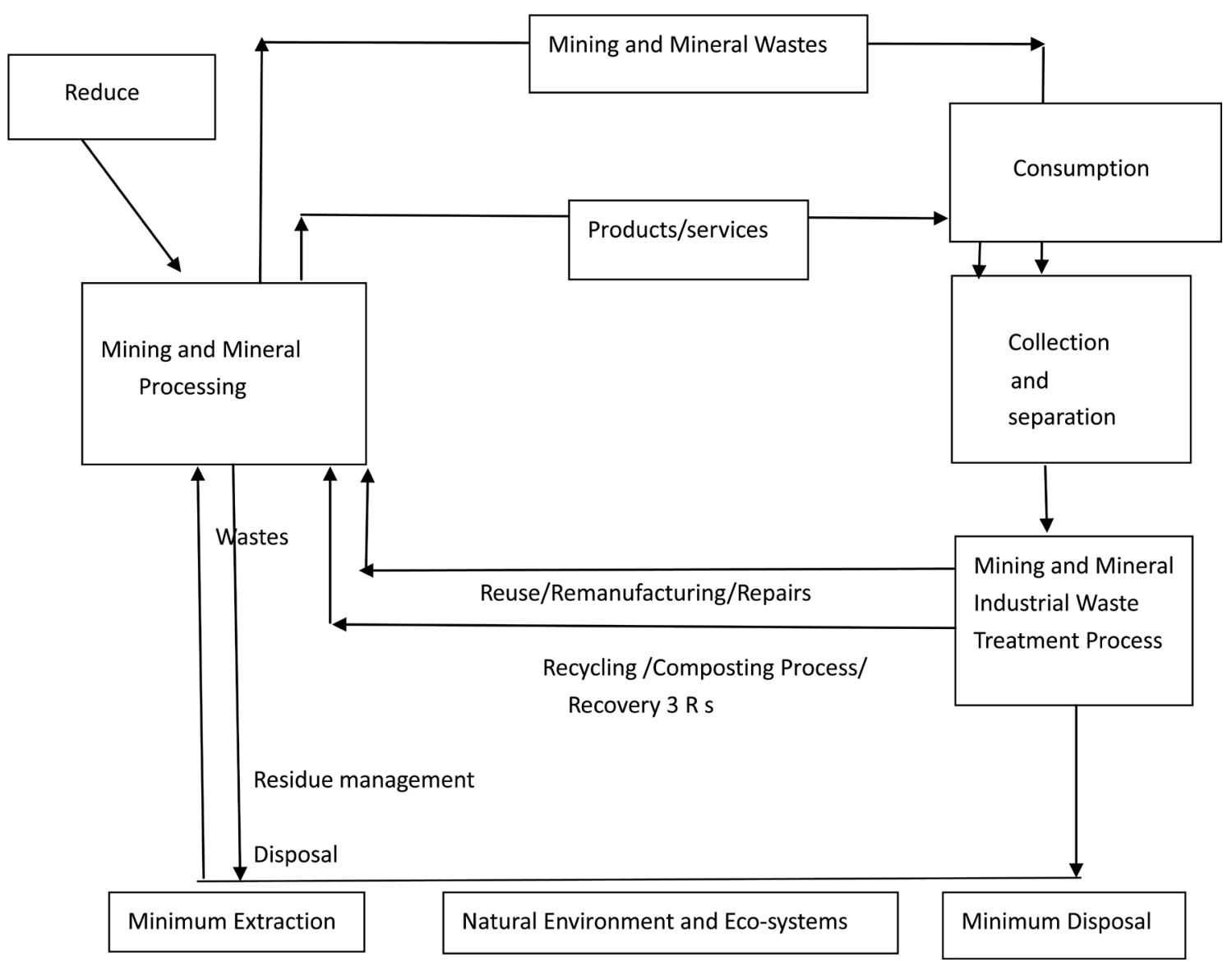

Figure 10. Closed-loop green economy for sustainable mining and mineral waste management. 


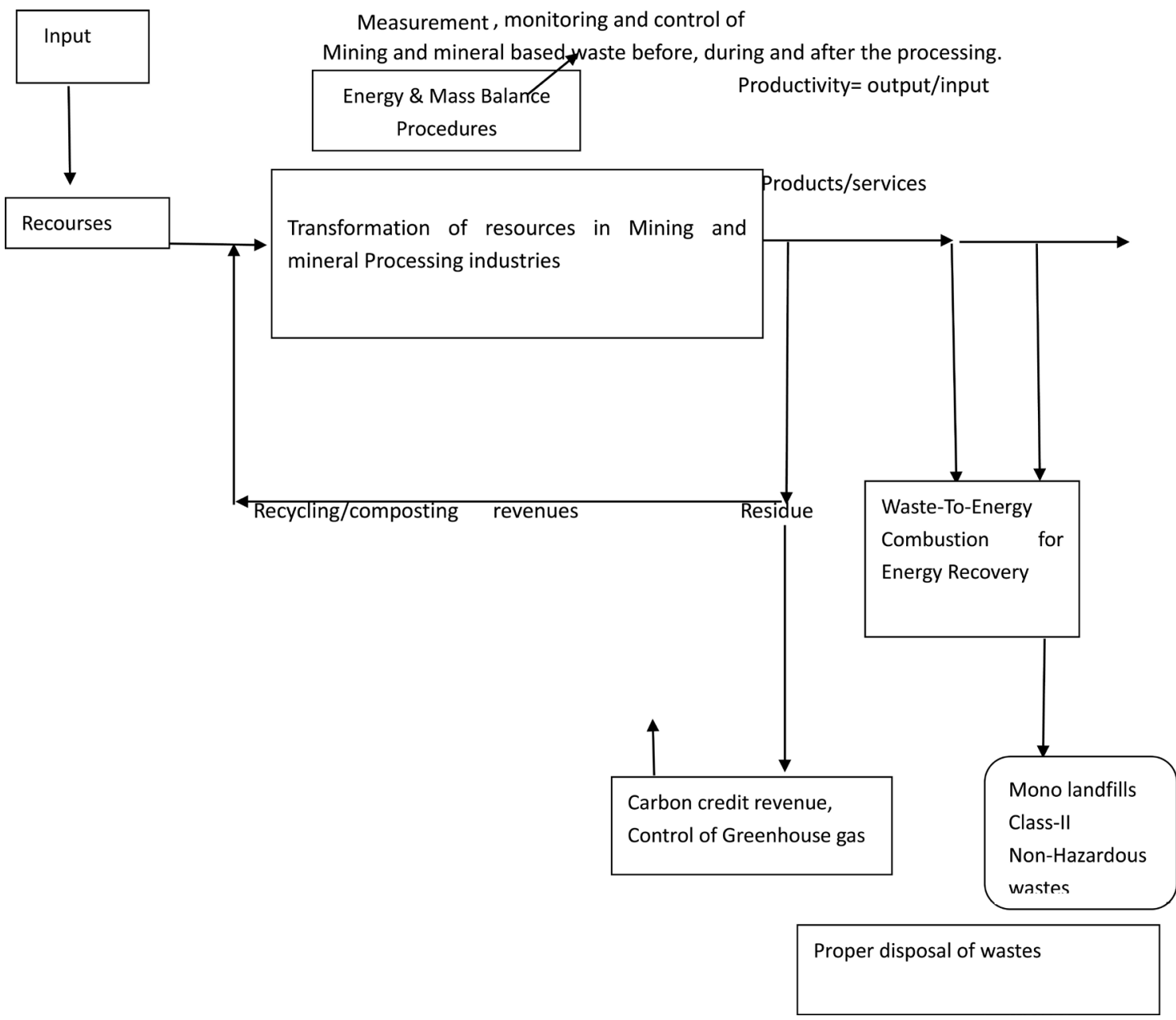

Figure 11. Schematic diagram for representing waste audit for a mining and mineral based industry for recovering two-third of wastes by formulating and appraising intensive recycling and composting programmes.

tion or money with which a business is started and run, and Sustainable technological momentum can be referred as total factor productivity (TFP) or efficiency in construction process. Such momentum keeps the capital development dynamic which emerges from the sustainable enterprise creation process, green products or services, new methods of production and processes, new construction management and transportation, new markets and new forms of mining and mineral industrial organizations. Standard Production Function (SPF) is expressed based on operation approach as

$$
Y=f(C, L)
$$

where $Y=$ Output, $C=$ Capital, and $L=$ Labor.

As knowledge is an important factor for the economic growth, Standard Production Function (SPF) is modified based on process approach as

$$
Y=A . f\left(X_{1}, X_{2}, X_{3}, X_{4}, X_{5}, X_{6}\right)
$$

“ $A$ " represents Knowledge on sustainable mining and mineral engineering or technical factor, $Y=$ Output and Input elements are namely, manpower, machinery, materials, method, money and market denoted as $X_{1}, X_{2}, X_{3}, X_{4}, X_{5}, X_{6}, \mathrm{f}=$ 
Standard production function.

As per the given standard production function, knowledge is a decisive production variation, sustainable innovation level is required in engineering or technical system. The solution is the development of reformed SEA implemented mining and mineral industries.

\subsection{Importance for the Conduct of Environmental Impact Assessment (EIA), Blast Impact Assessment and Management Study for the Mining and Mineral Based Projects}

Historically, the choice of new mining and mineral projects was primarily on one criterion that is economic viability. Presently, a second and third choice criterion that is environmental and social impact have become a strong yardstick, therefore a triple bottom-line approach that is economic, environmental and social factors to constructional project viability. It has been identified and evaluated that Blast impact assessment has to be conducted in the process Indian Mining and Mineral exploration and exploitation. Environmental Impact Assessment (EIA) process is a systematic identification and evaluation of potential effects of proposed projects, plans, programs, plans or legislative actions relative to the physical-chemical, biological, cultural and socio-economic components of the total environment. Blast Impact Assessment (BIA) process is a systematic identification and evaluation of potential blasting effects of proposed projects, plans, programs, plans or legislative actions relative to the physical-chemical, biological, cultural and socio-economic components of the total environment.

Steps to Conduct Environmental Impact Assessment and Management (BIA)

Step-1: Identification of quantity and quality characteristics of concerned environment of proposed project.

Step-2: Preparation of description of existing environmental resource conditions.

Step-3: Procurement of relevant quantity and quality standards.

Step-4: Impact predictions.

Step-5: Assessment of impact significance.

Step-6: Identification and incorporation mitigation measures.

\subsection{Conduct of Environmental Impact Assessment (EIA) (BIA) Study for Efficient Mining and Mineral Projects}

1) Prediction and assessment of impacts on surface water environment,

2) Prediction and assessment of impacts on soil and ground environment,

3) Prediction and assessment of impacts on the air environment,

4) Prediction and assessment of impacts on the noise environment,

5) Prediction and assessment of impacts on the biological environment,

6) Prediction and assessment of impacts on the visual environment,

7) Prediction and assessment of impacts on socio economic environment.

8) Prediction and assessment of impacts on cultural environment,

9) Prediction and assessment of impacts on archaeological environment, 
10)Prediction and assessment of impacts on anthropological environment.

\subsection{Benefits of EIA/BIA in Mining and Mineral Industries}

1) Considerable reduction in waste and the depletion of resources.

2) Considerable reduction and/or elimination of the release of pollutants in to the environment.

3) Green design and green building products to minimize their environmental impact in production, use, and disposal.

4) Control the environmental impacts of sources of raw material.

5) Waste minimization and adverse environmental impact of new developments.

6) Promote environmental awareness among employees and the community.

\subsection{Environmental Management (Blast Management) Programs}

The organization shall establish and maintain a program(s) for achieving the environmental objectives and targets. It shall include designation of the responsible function, team, or individual and a time frame for achievement.

1) State the objective/target.

2) State the purpose (how the objective/target will support the policy).

3) Describe how the objective/target will be achieved.

4) State the program (team) leader.

5) Designate departments and individuals responsible for specific tasks.

6) Establish the schedule for completion of the tasks.

7) Establish the program review, which will include format, content, and review schedule.

\subsection{Conduct of Social Impact Assessment (SIA) Study}

Social Impact Assessment (EIA) process is a systematic identification and evaluation of potential social effects of proposed projects, plans, programs, plans or legislative actions relative to the society. The purpose of the SIA process is to bring about sustainability and equitable biophysical and human environment [16]. SIA process includes the monitoring, measurement and control opportunities including analysis and management of the intended and unintended social consequences whether both positive and negative impacts of planned interventions and any changes takes place in social transformation process invoked by those interventions. The SIA process should include the analysis of the use of land, culture, industrial process, economic development, and their impact on service sectors such as water use, energy use, sanitation and traffic. SIA process is done to ensure that there is no mismatch between the constructional development and socio-cultural and economic development of the project areas.

\subsection{Sustainable Water and Waste Water Quality Management}

Water quality has been investigated which is to be maintained in mining and mineral sites such that water supply to consumers is safe and hygiene [17]. Rele- 
vant water quality standards are followed [17]. Sanitation impact assessment (SIA) has been done for finding the sanitation effects of proposed sanitation projects, plans, programs, policies, projects and legislative action. Sewerage system, Waste water treatment system, industrial waste treatment system, storm water drainage system and sustainable septic tank are important onsite requirements. Relevant waste water discharge standards are to be followed. Process approach for measurement, monitoring and control opportunities for water, waste water and industrial water quantity and quality has been meticulously followed [17].

\subsection{Safety Engineering and Management in Mining and Mineral Industries as Safety First}

Safety management is the systematic identification and evaluation of potential safety requirements of proposed projects, plans, programs, plans or legislative actions. The purpose of the safety engineering and management is to bring about design and constructions of sustainable mining and mineral engineering structures. It has been observed that conventional mining and mineral extraction methods and machineries employed are to be obsolete and outdated because they seem very old which operated on poor performances in terms of productivity, quality, efficiency and safety. Some of the alternative machineries, which are indigenously manufactured, also do not guarantee for the safety performance and because of their poor design and materials of construction. It is mandatory that checking for safety requirements with regard to machineries and plant. Safety personnel responsible for overseeing the safety of all operating personnel must be cognizant of the latest laws and regulations pertaining to miner's safety and occupational health [18]. These are changed and/or updated from time to time. Checking for Safety (CFS) such that to ensure that the question of safety will not be overlooked, it is well to have all plans, specifications and drawings checked for safety, making special provision for this in each set of specifications and in the title plate of each drawing duly checking periodically for cranes, hoists, ventilation, lifts, tackles, fire protection systems, alarms, buildings, mechanical guarding and electrical and electronic equipment and heavy engineering equipment. Personal protective equipment's (PPEs) and materials include garments, clothing, gloves, safety shoes, hard hats, safety glasses, shields, respirators, full aprons, safety belts, and other safety items used by an individual [18]. Such equipment is important for personal protection and for safety. It is the manager's and supervisor's responsibility to ensure that they are used.

As far as occupational-disease prevention is concerned that those persons engaged in or working near operation are exposed to appreciable quantities of dusts, fumes or gas, it is important that adequate control measures must be adopted. Some major considerations involved in the application of effective control to industrial occupational disease are given. Some of the policies, practices, and procedures to prevent exposure of personnel to unsafe materials are also provided. As far as the miner's compensation law is concerned, it must be enacted strictly in our country. The principle involved is that the miner injured 
or disabled in construction industries should be enabled, through proper medical treatment, to return to wage-earning capacity as promptly as possible and while incapacitated, should receive compensation in lieu of wages, and regardless of fault. The expense of medical treatment and compensation should properly be borne by industry and become a part of the cost of its products. The laws generally provide that miners injured in industry shall be furnished the necessary medical treatment, and, in addition, compensation based on a percentage of their weekly wages, payable periodically. Dependents of employees kill in industry are likewise compensated. Occupational diseases law provides provisions for compensation benefits in occupational-disease cases. The enactment of miner's compensation laws and occupational disease law shall increase materially the cost of insurance to industry. The increased cost and the certainty with which it is applied will put a premium on accident-prevention work. This cost can be materially reduced by the installation of safety devices [18]. Research experience has shown that approximately $80 \%$ of all the construction industrial accidents are preventable [18]. As far as the fire loss prevention is concerned, it is an indispensable element in mining and mineral industry. It exists only with top management direction and the support of labor. The designation fire protection usually encompasses the entire field of prevention of loss by fire, including both the causes for the occurrence of fires and methods for minimizing their consequence. Some of the fire standards of protection to prevent injury and loss of life are given in this paper. Fire protection engineering practices both in building design and in safe operating practices are also included [19]. As far as mining noise safety is concerned, noise is recognized as a pollutant, both as a nuisance and as the cause of hearing impairment. Blasting impact assessment should be conducted for certain blasting projects. There is evidence in construction sites that noise cause ailment such as hearing impairment, physiological and psychological disorders including anxiety and heart disorders. Protection from noise is required when sound levels exceed those standards. When protective equipment is required, it must be provided by a trained person and periodic checks made of the effectiveness [19].

\subsection{Total Quality Management (TQM)}

Total Quality Management (TQM) can be broadly defined as a set of systematic activities carried by an institution to efficiently achieve institutional objectives that satisfies beneficiaries at the appropriate time and price. The definition of quality is "The totality of features and characteristics of products or services that bear on its ability, efficacy and values to satisfy a given or implied need". TQM is a comprehensive and structured approach to an educational integrated management that seeks to improve the quality of educational services through ongoing refinements in response to continuous feedback. Thus this standard definition of quality is applicable commonly to both products and services that is stated and unstated. TQM has an important role to play in addressing quality issues surrounding the constructional development. TQM is a comprehensive 
and structured approach to mining and mineral sector that seeks to improve the quality of services through ongoing refinements in response to continuous feedback. TQM leads to sustainable mining and mineral development. International Organizational for Standardization's ISO 9000 series define TQM as a management approach centered on right quality and uniformity, based on the participation of all its members and aiming at long term success through customer satisfaction and benefits to all members of the organization and society. Hence, TQM is based on quality management from the customer's point of view. TQM processes are divided into four sequential categories: plan, do, check, and act (Figure 12). This is also called the PDCA cycle or Deming's cycle for continuous process improvement. In the planning phase, miners define the problem to be addressed, collect relevant data, and ascertain the problem's root cause; in the

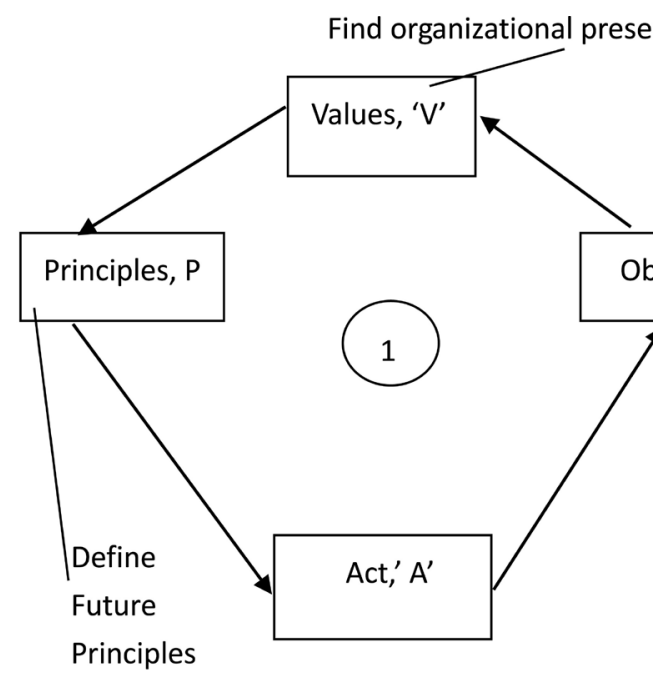

OVPA Cycle is a Culture based Cycle for Values

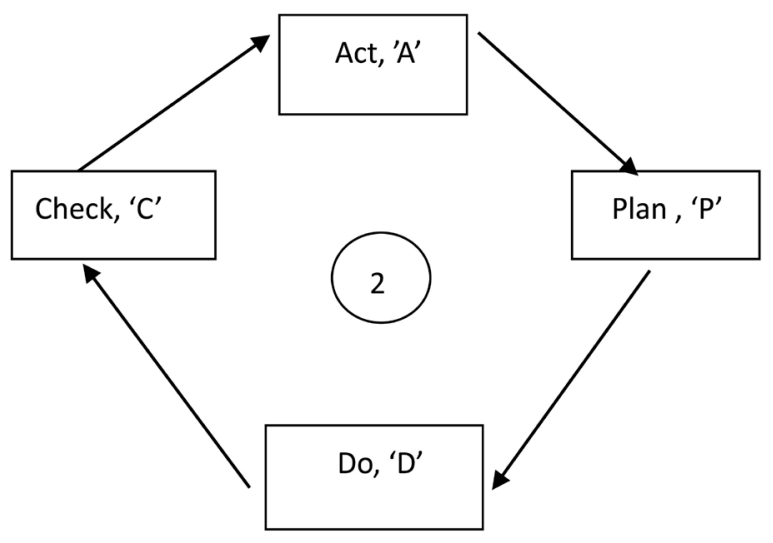

PDCA Cycle for Continuous Process improvement

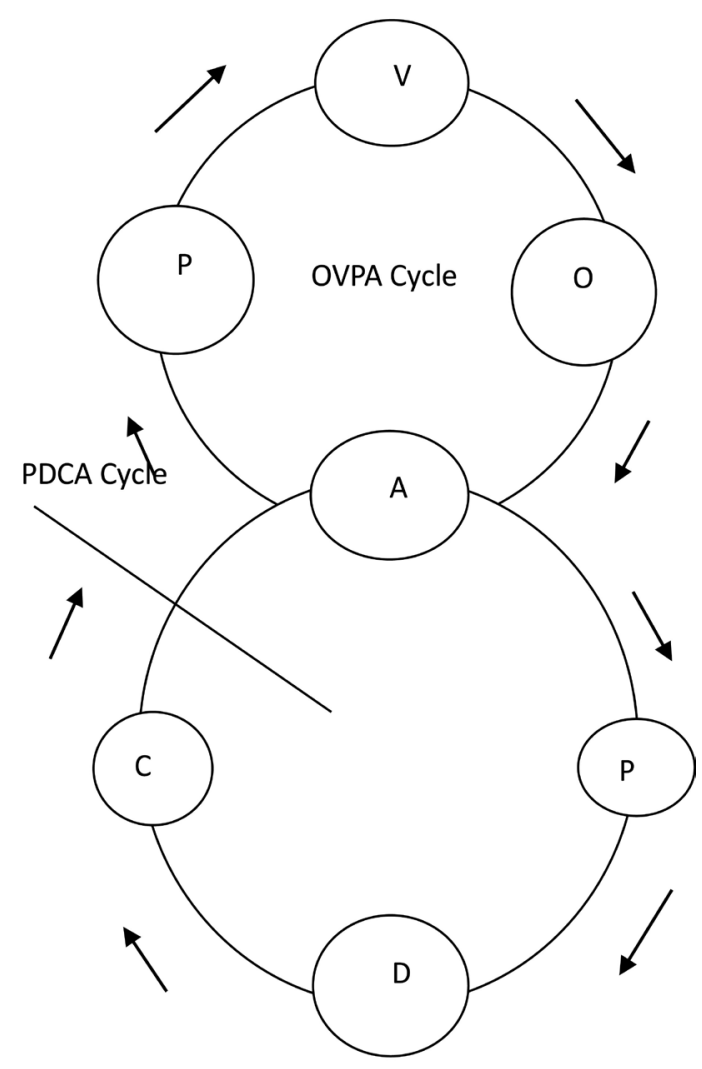

Expanded PDCA Cycle

Figure 12. Conceptual culture based environment and sustainability management system entitled "OVPA" cycle by incorporating the expanded PDCA cycle for SEA process in mining and mineral industries. 
doing phase, miners develop and implement a solution, and decide upon a measurement to gauge its effectiveness and efficiency; in the checking phase, miners confirm the result through before-and-after data comparison; in the acting phase, miners document their results, inform others about process changes, and make recommendations for the problem to be addresses in the next PDCA cycle. ISO 9000 series focus on quality management for all sorts of organizations. It defines the features of quality management system (QMS) that need to be in place to ensure that identify and focus on improving the areas where they have significant mining and mineral engineering deficiencies.

The ISO 14,000 Environmental Management System (EMS) standards apply to the management system to manage an organization's environmental issues and opportunities. It defines the features of an EMS that need to be in place to ensure that the organization identifies and focuses on improving areas where they have significant environmental impacts. This system has been integrated with ISO 9000 Quality Management System (QMS) standards to achieve excellence in quality as well as environmental obligations in midget electrode project. The overall aim of the EMS is to provide protection to the environment and to prevent pollution to manufacture eco-friendly products and services. The ISO 14,000 series of standards assist the organizations to excel environmental and economic gains for continuously improving organizational performances. They are used for prevention of pollution, reduction in wastes, enhancement of internal management system efficiency, optimum utilization of resources and compliances for legal and regulatory requirements. EMS can be basically divided into five events which form the sequence of a cycle (Figure 13). These five events are

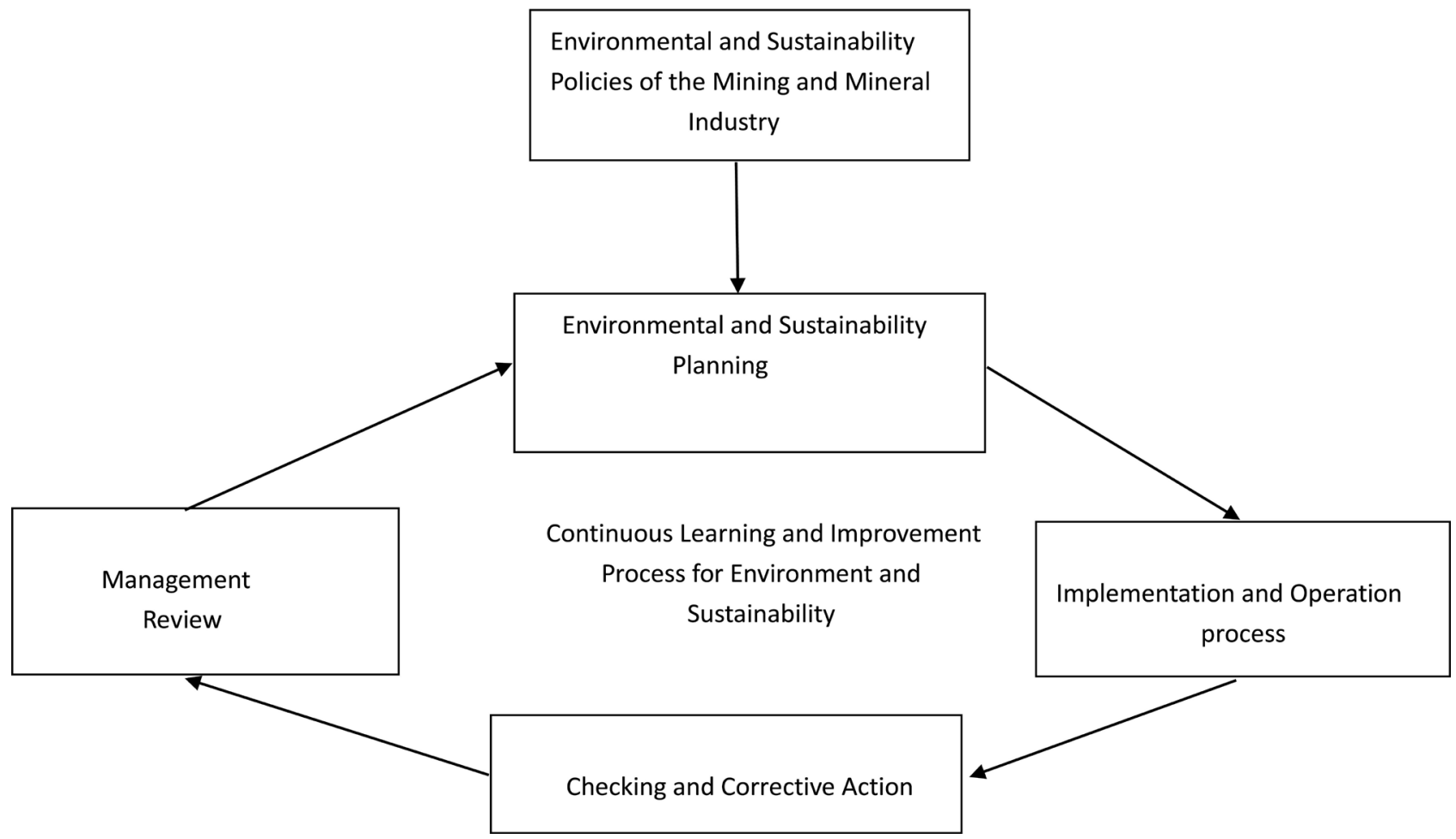

Figure 13. Environment and sustainability management system for mining and mineral industries. 
1) Environmental Policy, 2) Environmental Planning, 3) Environmental implementation and operations, 4) Checking and corrective actions, and 5) Management Review. The ISO 14,000 series of standards have also been designed to cover the areas of environmental issues and opportunities for the organizations to compete the global customer centric markets so that the products and services can be manufactured at par with the international requirements.

EMS focuses on key drives of performance excellence in products and processes as well as organizations that are focused on delivering values to the customers, internal operational processes, and to staff s learning. It may be mentioned that Environment and Quality Management (EQM) is a managerial approach centered on environment and right quality through beneficiary satisfaction in mining and mineral industries that lead to economic improvement and sustainability. Hence, this system approach to the environmental management shall achieve excellence in the overall performances of the organization.

\section{Conclusions}

SEA process has been aimed to incorporate environmental and sustainability factors into mining and mineral project planning and decision making process, such as projects' formulation and appraisal of Indo-Matsushita midget electrode (battery carbon rod) plant in 1979 at Tada, blasting projects and Odissa chromite mining plants that included projects, polices, programs, plans and legislative actions. The primary purpose of the SEA process is to encourage the consideration of the environment, safety, health, social and sustainability factors in an organizational MMPPDM process and to arrive at actions that are compatible. EIA/BIA should be considered as an official tool to protect the environment. EIA process is a multidisciplinary approach that must be necessary in providing a prevention mechanism for environmental management and protection in any mining and mineral processing development. EIA process is designed to identify and predict the potential effects of the physical, biological, ecological, socioeconomic, cultural environment and on human health and well-being that are adequately protected. As per research results, MMPDM process should include the integrated consideration of technical or engineering, economic, environmental, safety, health, social and sustainability factors to achieve business excellence.

The SEA process protocol has been proposed for checking the right quality of environmental and social assessments and management plans. This treaty and official government procedures of SEA are helpful for making much earlier in the decision-making process than EIA/BIA process. Therefore, it is key tool for sustainable development. SEA aims to incorporate environmental and sustainable considerations into strategic decision making processes to formulate policies, plans, and programs and legislative actions. Prior to the National Environmental Policy Act (NEPA) process in 1970 in the USA, technical and economic factors dominate the World's constructional projects. The objective of the study was to conceptualize SEA process for the construction sector based on fifteen numbers 
of sustainable detailed project reports submitted by the extension learners of Diploma in Entrepreneurship and Business Management course conducted by the Entrepreneurship Development Institute of India during the research year 1999 to 2016 under the author's counsellorship. The ISO 14,000 Environmental Management System standards should apply to the management system concepts of total quality management to the management of an organization's environmental issues and opportunities. It defines the features of an EMS that need to be in place to ensure that organizations identify and focus on improving areas where they have significant environmental impacts. EMS focuses on key drives of performance excellence in products and processes as well as organizations that are focused on delivering values to the customers, internal operational processes, and to staff's learning. Hence, this system approach to the environmental management shall achieve excellence in the overall organizational performance. Mining and Mineral Engineering industrial product environmental lifecycle analysis has been conducted for identifying and measuring the impact on the environment and sustaining efficacy. LCA considers the activities related to raw materials, transformation, ancillary materials, equipment's, methods, market, production, use, disposal and ancillary equipment. As far as the mining and mineral safety is concerned, personal protective equipment and materials that include garments, clothing, gloves, safety shoes, hard hats, safety glasses, shields, respirators, full aprons, safety belts, and other safety items should use by an individual. Such equipment is important for personal protection and for safety. It is the manager's and supervisor's responsibility to ensure that they are used. The enactment of miner's compensation laws and occupational disease law shall increase materially the cost of insurance to industry. The increased cost and the certainty with which it is applied will put a premium on accident-prevention work. This cost can be materially reduced by the installation of safety devices. Mining and mineral management research experience has shown that approximately $80 \%$ of all the industrial accidents are preventable. It is concluded that eenvironment coupled with right quality management is a managerial approach centered on environment and quality through beneficiary satisfaction that leads to economic improvement and sustainability based on the triple bottom-line approach. TQM has an important role to play in addressing right quality and uniformity issues surrounding the sustainable mining and mineral management development.

Unsafe chromium and environmental health impact assessment (EHIA) process for Odissa chromite mining plants was investigated to mitigate psychological and physiological health impact loadings on miners and nearby residents. Odissa accounts for 95 percent of the chromium ore reserves of India. Indian Odissa chromite mines generate considerable quantity of pollutants containing toxic hexavalent chromium, a known carcinogen, which contaminates $10-4000$ $\mathrm{mg} / \mathrm{kg}(\mathrm{ppm})$ of total chromium in air, water and land environment as against the safe limits of $0.1 \mathrm{mg} / \mathrm{l}$. Surface water and ground water in Sukinda region contain hexavalent chromium (CrVI), well above the permissible limits of 0.05 
$\mathrm{mg} / \mathrm{l}$ (ppm). Exposure to chromium on humans can occur through the three major routes, via. absorption through the skin, by direct ingestion and by inhalation of chromium containing particles. The oral $\mathrm{LD}_{50}$ of chromite in humans has been reported to be $50 \mathrm{mg} / \mathrm{l}(\mathrm{ppm})$. There are clusters of chromite mines release considerable quantity of effluents and slurries, as well as the over burden stockpiles as hazardous wastes. Suspended and respirable particulate matter was found well above the prescribed limit of $100 \mu \mathrm{g} / \mathrm{m}^{3}$. Chromium based diseases among the miners and nearby residents were observed which could be a result of the intake of excessive $\mathrm{Cr}(\mathrm{VI})$. There are about 15 chromite mines which are in Sukinda discharges copious amount of mine water which has $\mathrm{Cr}(\mathrm{VI})$ concentrations up to a value of $15 \mathrm{mg} / \mathrm{l}$ and ground water has $6 \mathrm{mg} / \mathrm{l}$ as against the safe limits of $0.1 \mathrm{mg} / \mathrm{l}$. In few places, even nickel was found in concentrations up to $0.6 \mathrm{mg} / \mathrm{litre}$. Chromite miners and nearby residents, who were constantly exposed to contaminated dust and water, report gastrointestinal bleeding, tuberculosis and asthma besides incidence of infertility, birth defects and still births. Mine water is discharged into various tributaries of the Brahmani river. This unsafe chromium pollution produces adverse health effects on the people who are exposed in their vicinity. They suffer from chromium based diseases such as chromium poisoning, ulcer, allergic dermatitis, lung cancer, lever necrosis, brain damage, premature death, lever and kidney problems. As per the medical evidence reports, it is necessary to take regulatory measures to control chromium pollution problem in Orissa State. Chromium effluent treatment plants (CETP) must be incorporated to mitigate the adverse health effects. It is essential to evolve preventive and control strategies at the planning stages as prevention is better than cure, very little or nothing can be done if the toxic chromium reaches the air, water and soil environment. Miner's compensation laws and occupational diseases law should be implemented for the welfare of miners and nearby residents. As per the management studies conducted, it has been proved that approximately 80 percent of mine disasters are preventable provided factory laws get enforced.

SEA system is a potentially useful element of good environmental management and sustainable development; however, as currently practiced in mining and mineral industries, it is far from perfection. Emphasis should be given in mining and mineral industries on maintaining economic viability of the operation, while in turn taking care to preserve the ecological and social sustainability of the country. International EIA process required multi-disciplinary approach that has been conducted very early stage of Indo-Matsushita carbon rod project in 1982 at Tada for economic, environmental and social. The SEA process protocol has been proposed for checking the quality of environmental and social assessments and management plans. This treaty and official Government procedures of SEA helpful for making decisions much earlier in the decision-making process than EIA and BIA. Therefore, it is key tool for sustainable development. SEA aims to incorporate environmental and sustainability considerations in to strategic decision making processes to formulate sustainable projects, 
policies, plans, programs and legislative actions.

\section{Acknowledgements}

The author is thankful to Entrepreneurship Development Institute of India (The EDI of India) for attaching fifty three number of DEBM extension learners to counselor and coordinator and award of DEBM to fifteen learners during the RY 1999-2016. The author is thankful to Prof. (Dr.) Rao of Regional Research Laboratory (RRL), Bhubaneswar for providing necessary guidance. The author is thankful to the Managing Directors of M/S Panasonics Carbon India Company Ltd. (PCIN) Formerly known as M/S Indo-Matsushita Carbon Company Ltd. (IMCCL), Tada, Sullurpeta District, Andhra Pradesh for co-operation during the project phase (1982-1984) and updated sustainability and environmental studies (2017). The author is thankful to Sri. Mittapalli Venkata Koteswara Rao, Chairman of Narasaraopeta Engineering College (Autonomous), Affiliated to JNTUK, Guntur District, and Andhra Pradesh for encouragement to publish this research work. Further the author is thankful to the Mining Engineers' Association of India (MEAI) for publishing this work in the Souvenir and Proceedings of the $3^{\text {rd }}$ International Conference on Advanced Technology in Exploration and Exploitation of Minerals held during 20-22 January 2017.

\section{References}

[1] Iyer, V.G., et al. (2012) Ecological Impact Assessment for Prediction and Assessment of Impacts on the Biological Environment with respect to Indian Scenario. Proceedings of the 2nd International Conference on Environment, Economics, Energy, Devices, Systems, Communications, Computers, Mathematics, France, 2-4 April 2012, 61-66.

[2] Canter, L.W. (1996) Environmental Impact Assessment. 2nd Edition, McGraw-Hill International Editions 1996, 1-93.

[3] Glynn, H.J. and Heinke, G.W. (2002) Environmental Science and Engineering. 2nd Edition, Prentice-Hall of India Private Limited, 34-57.

[4] Iyer, V.G. (2011) Ecological Impact Assessment for Prediction and Assessment of Impacts on the Biological Environment. In Abstract Book of NASI Reference Abstract Index Number B167/2011 of the 81 st Annual Session of The National Academy of Sciences, India (NASI) during the National Symposium on Sustainable Management of Bio-Diversity Using Science and Technology Held on November 24-26, 2011 at University of Kerala, Thiruvanthapuram, 23.

[5] Iyer, V.G. (2011) Environmental Health Effects of Unsafe Pollution Lead-A Synergistic Modeling Approach to Find Environmental Impacts. Proceedings of Recent Researches in Environment, Energy Planning and Pollution of the 5 th WSEAS International Conference on Energy Planning, Energy Savings, Environmental Education EPESE 11), Iasi, 1-3 July 2011, 132-139.

[6] Iyer, V.G. (2003) Environmental Effects of Chrome Rollers Used by Cotton Roller Ginning Industries and Design and Development of an Eco-Friendly Alternative. PhD Dissertation, Indian School of Mines (ISM), Dhanbad, 23-57.

[7] Iyer, V.G. (2010) Environmental Impact Assessment of Hazardous Industries and Application of Cleaner and Greener Technology. 3rd WSEAS Together with Constantza Maritime University, International Conference on Environmental and Geo- 
logical Science and Engineering (EG10), Energy and Environmental Engineering Series (A Series of Reference Books and Text Books), Constanza, 3-5 September 2010, 218-234.

[8] Iyer, V.G. (1997) Studies on Environmental and Health Effects of Chrome Composite Leather-Clad Roller Commonly Used By Cotton Roller Ginning Factories and Development of Pollution-Free Rubberized Cotton Fabric Roller. M.Tech. Dissertation, Indian School of Mines, Centre of Mining Environment, 65-90.

[9] Iyer, V.G., et al. (2010) Unsafe Chromium and Its Environmental Health Effect of Orissa Chromite Mines. Proceedings of the WSEAS Conference on Energy and Environmental Technologies and Equipment (EEETE10), Energy and Environment series, a Series of Reference and Text Books, Universitatea Politecnica, Bucharest, Romania, 111-122.

[10] Iyer, V.G., et al. (2009) Unsafe Chromium and Its Environmental Impact Assessment. Proceedings of the WSEAS 2nd International Conference on Environmental and Geological Science and Engineering (EG09), Transilvania University of Brasov, Romania, 24-26 September 2009, 50-56. http://www.wseas.us/conferences/2009/brasov/eg

[11] Iyer, V.G. (2016) Strategic Environmental Assessment (SEA) Process towards Sustainable Construction Management Development for the Indian Construction Industries to Achieve Business Excellence. International Conference on Construction, Real Estate, Infrastructure and Projects Management (ICCRIP), Pune, October 2016, 21-22.

[12] Iyer, V.G. (2007) Correct Practices and Guidelines for Applying Occupational Safety and Health Standards in Coal Mining Industries. Book of the Proceedings of the First International Conference on Managing Social and Environmental Consequences of Coal Mining in India, New Delhi, 19-21 November 2007, 233-248.

[13] Iyer, V.G. (2006) Environmental Management System for the Organizations to Achieve Business Excellence. Proceedings of the International Conference on Sustainable Energy and Environment, Bangkok, 21-23 November 2006, 1032-1037. www.see2006.com

[14] Iyer, V.G. (2016) Environmental Health Impact Assessment (EHIA) Process towards Environmental Health for All. The 3rd World Conference on Health Sciences (HSCI-2016), Kusadasi, 28 April-30 May 2016, 88. http://www.h.sci.org http://worldeducationcenter.edu

[15] Iyer, V.G. (2014) Unsafe Chromium from Cotton Ginneries in Ethiopia and Development of a Rubberized Cotton Fabric Roller for Cotton Roller Gins. National Symposium on Science, Technology and Innovation for National Development, Nekemte, 21-22 March 2014, 49. http://www.starjournal.org/wu-press.html

[16] Giri., C.C., et al. (2003) Importance of the ISO 14000 in Textile Industry and Its Implementation Framework. Journal of Textile Association, 57-63.

[17] Metcalf Eddy, Inc. (2012) Wastewater Engineering, Treatment and Reuse. 3rd Edition, McGraw Hill Education (I) Private Ltd., Auckland.

[18] Pascal, M.R. and Klein, A.C. (2007) Occupational Safety and Health. 11th Edition, McGraw-Hill Professional. https://accessengineeringlibrary.com

[19] Pascal, M.R. and Klein, A.C. (2007) Fire Protection Handbook. 11th Edition, McGraw-Hill Professional. https://accessengineeringlibrary.com 
Submit or recommend next manuscript to OALib Journal and we will provide best service for you:

- Publication frequency: Monthly

- 9 subject areas of science, technology and medicine

- Fair and rigorous peer-review system

- Fast publication process

- Article promotion in various social networking sites (LinkedIn, Facebook, Twitter, etc.)

- Maximum dissemination of your research work

Submit Your Paper Online: Click Here to Submit

Or Contact service@oalib.com 